\title{
Bedside healthcare rationing dilemmas: a survey from Croatia
}

\author{
Micaela Pinho, Ana Borges and Duje Petricevic
}

\begin{abstract}
Purpose - The purpose of this paper is to explore Croatian views about issues regarding bedside rationing decisions.

Design/methodology/approach - An online questionnaire was used to collect data from a sample of 243 Croatian citizens. In a context of hypothetical scenarios involving priority setting decisions taking by physicians, the present study elicits Croatian respondents' views concerning: the ethical principles that should guide patients prioritization; the parties that should make prioritization decisions; and the likelihood of healthcare rationing becoming a reality. Descriptive analysis, factor analysis and parametric and nonparametric tests were performed.

Findings - Findings suggest that Croatian respondents: support multiple substantive rationing criteria, with an incident in favoring the worst-off, reducing inequalities in health, translated in the fair-innings argument and efficiency achievement; appoint health professionals as rationing decision makers; and do not seemto believe in the possibility of patient selection becoming a reality.

Practical implications - Favoring the worst-off, equalizing life time health and the pursuit of efficiency seem to be the criteria most preferred by Croatian respondents to guide rationing policy at the micro level.

Originality/value - This study is the first attempt to elicit Croatian opinions concerning several rationing criteria inherent in healthcare micro allocation decisions. Healthcare rationing is a serious challenge to Croatian policy makers and so it would be useful for the public's perceptions and beliefs to be considered.
\end{abstract}

Keywords: Croatia, Ethical principles, Healthcare rationing, Patientsu2019 prioritization

Paper type Research paper

\section{Introduction}

Rationing or priority setting (terms we will use interchangeably, following Coulter and Ham, 2000) occurs at every level of every health system and is one of the most significant healthcare policy issues of the twenty-first century. Priority setting remains a big challenge to policy makers worldwide despite the growing research that has been done in this area. At the micro level, physicians have to manage the competing claims on their limited budgets, which are fixed at the macro level. They have to decide which patients to attend to first or, ultimately, which ones not to treat at all. The economic approaches to healthcare micro allocation have had a limited success, partly because they do not properly incorporate the ethical considerations, which the physicians and the public face, when making rational priority setting decisions (Mitton and Donaldson, 2004). Eventually, the need to take the responsibility off the shoulders of the physicians will emerge, sparking an open discussion with regard to the principles or criteria which should guide the establishment of priorities among patients. Different principles have been proposed (Williams and Cookson, 2000; Persad etal., 2009; Beauchamp and Childress, 2012). Additionally, there is a growing empirical literature on the views of the general public in different countries (Cookson and Dolan, 1999; Kaplan and Baron-Epel, 2013; Diederich and Salzmann, 2015; Exel et al., 2015; Gu et al., 2015; Pinho and Borges, 2015; Rogge and Kittel, 2016; Pinho et al., 2017). The results seem to indicate that the public supports multiple ethical principles and that those values vary at a cultural level. Therefore, a successful policy of healthcare priority setting must take into account the values and culture of the population for which it is intended.
Micaela Pinho is based at the Research on Economics, Management and Information Technologies (REMIT), Portucalense University, Oporto, Portugal andResearch Unit in Governance, Competitiveness and Public Policies (GOVCOPP), University of Aveiro, Aveiro, Portugal.

Ana Borges is based at the Lusíada University of Oporto, Oporto, Portugal.

Duje Petricevic is based at the University of Split, Split, Croatia. 
In Croatia, no attempt has ever been made to elicit preferences regarding the ethical principles that should guide bedside rationing decisions. This research is particularly relevant because, since the early 1990s, the Croatian health system has been subject to reforms that aim to increase efficiency and contain costs. The rationing of services, penalties for excessive prescribing or referrals, creation of a limited list of approved drugs, reduction in health budgets and increases in copayments were some of the measures implemented (Mastilca and Kusec, 2005; Vončina et al., 2012; Dzakula et al., 2014). These reforms have increased dissatisfaction with the public health system and deepened health inequalities especially when comparing the health service use of low- and high-income groups (Mastilca and Kusec, 2005). According to the recent data, in 2014, around 8 percent of the Croatians under 16 self-reported unmet needs for medical examination, due to the care being too expensive, too far to travel to or because of an existing waiting list, when compared to the average of 5 percent in the EU28 (Eurostat, 2016). The pursued health reforms did not involve the population in any way, contrary to what is stressed in the Ljubljana Charter on Reforming Health Care (WHO Regional Office for Europe, 1996). The advent of the recent economic recession has placed Croatia's health system under pressure (as many other European health systems), with real funding cuts, which forces the policy makers to face rationing in a serious and systematic manner. Hence, it is worth asking whether Croatians are aware that healthcare will, in a near future, no longer be provided to all who need it? If so, which particular prioritization principles will the Croatian population support? Whom do they trust to take the prioritization decisions?

In this paper, we undertook a comprehensive analysis in order to answer the above questions. Our overall goal is to identify the acceptable criteria for guiding decisions with regard to establishing priorities at the micro level, in the Republic of Croatia. In a context of day-to-day healthcare priority setting decisions, taken by physicians, we aim to explore Croatian ethical principles concerning bedside rationing decisions, which parties they deem responsible for taking thesedecisions on their behalf and finally if they areaware that patients prioritization will becomea reality in a near future.

This study is the first to assess, in a systematic manner, the Croatian publics' views in relation to healthcare rationing issues.

\section{What principles could guide patients' prioritizations?}

One of the main constraints on implementing an explicit rationing approach, at the micro level, lies in the specification of the ethical principles that should be adhered to. Many substantive principles have been proposed in the theoretical literature, each representing a different interpretation of distributive justice. We based the research on the following: to each so as to maximize health gains, to each so as to favor those worst-off and to each so as to treat the patients equally.

Maximizing the health gains is a utilitarian value, although there is heterogeneity in defining health benefits. Health economists advocate the use of quality-adjusted-life-years (QALYs) as a measure of health benefits. The advantage of this measure is that it adjusts mortality and morbidity. The rationing decisions consist of maximizing QALYs by unit of cost. In this context, patients that benefit more from treatment (measured in years or quality of life), or that require cheaper treatments, should be prioritized. However, people may value the components of health gains differently. While some studies suggest that quality of life enhancement is preferable to life extending (Whitty et al., 2008; Diederich and Salzmann, 2015; Exel et al., 2015; Pinho and Borges, 2015), others indicate quite the opposite (Gu et al., 2015). Beyond these direct effects, the future savings to the health system should also be considered, such as the lack of need for future treatments.

Favoring the worst-off is an equity value that focuses on the Rawlsian differences principle (Rawls, 2002). It providesa positive discrimination by the stipulation of unequal consequences for those involved, since they result in compensatory benefits to the least advantaged members of the society. Healthcare is seen as a means of protection and reaching of equality of opportunities (Daniels, 1985). Le Grand (1991) proposed a broader notion of substantive equality of opportunities. Accordingly, differences in health outcomes do not count as 
inequitable, if they result from informed choices. Thus, it is equitable to treat people whose behavior has contributed to their ill-health differently from people whose ill-health has no such association. Aged-based rationing and allocation in accordance with the severity of the health conditions are two additional criteria toward favoring those worst-off. Although not consensual, the idea of prioritizing younger patients has received much attention in the literature. Callahan (1995), a Prominent Advocate of rationing by age, proposed some age cut-offs forscarce, life-saving interventions. The fair-innings argument, proposed by Williams (1997), supports an allocation system based on individuals' deviation from a normal life span. The goal is to provide all the individuals with equal opportunities of living a normal life span. Concerning the severity of health conditions, the rule of rescue argument describes a powerful psychological impulse to save those facing death, no matter how expensive or how small the chance of benefit (Jonsen, 1986).

The rationing principle based on treating all the patients equally is a compromise between the moral imperative and the egalitarian allocation strategies. This recognizes equal chances of accessing scarce interventions and avoids the responsibility of setting priorities among patients. Patients should thus be selected by lottery or through the strategy of "first come first served."

\section{Methodology}

The present study was organized according to three aims. First, to explore the degree of Croatian citizens' preference of prioritizing patients with regard to the distributive principles most discussed in the literature (described above). Second, to ascertain whom the Croatian respondents entrust with making rationing decisions and to examine how aware they are of rationing decisions becoming a real prospect infuture.

\section{Questionnaire}

The data were collected through an online questionnaire, made available on the social networks between March and June 2016. Eligibility criteria specified that participants should be Croatian speakers, 18 years of age or older and resident in Croatia. Respondents were recruited via Facebook, Twitter, LinkedIn, online discussion chat rooms and e-mail. The invitation to participate in the survey was sent by Croatian associates. Hence, it is a biased sample and thus not representative of the Croatian population.

The questionnaire was anonymous and was preceded by a sheet explaining the scope of the study and the requested permission to use the data obtained.

The questionnaire included four mandatory sets of questions. The first two questions consisted of a hypothetical rationing exercise, which was designed elsewhere (Cookson and Dolan, 1999) and previously applied in Portugal (Pinho and Borges, 2015) and in Bulgaria (Pinho et al., 2017). The scenarios described four patients, distinguished by their personal characteristics and health statuses (Tablel). The exercise consisted in putting respondents in the role of a hospital decision maker, facing two particular kinds of resource constrains. In the first question, respondents had to decide among the four patients, namely, whom to treat when there are no available resources to treat all of them. In the second question, respondents were asked to

\section{Table I Hypothetical scenarios described in the first two questions of the questionnaire}

Suppose that you are a decision maker in a hospitalwith resources to treat

Question no. 1: only one of the following patients Who would you choose?

Question no. 2: all patients but not at the same time

Indicate your order of priority

(1st higher priority and 4th lower priority)
Ivan is 18 years old and suffered a road traffic accident which resulted in severe facial scarring and psychological problems. Plastic surgery would correct the scarring

Marija is 45 years old, is single, with no children. She was diagnosed with hepatitis $B$ as a result of their long years of drug consumption. Maria has not consumed drugs for 5 years. There is a treatment available, which is $75 \%$ effective and it will provide years of quality life Ruža is 65 years old and is almost blind. She waited 3 years for a surgery to remove cataracts. Her blindness has worsened over time and soon she will no longer be able to live alone. She has no family. The operation will allow her to be independent

Petar is 8 years old and has leukaemia. The probability of survival is of $50 \%$. But there is a new treatment available that it has been partially tested in a few cases 
establish an order of treating the four patients, assuming that the resources available allow for the treatment of all the patients, but not at the same time. The authors' purpose was to evaluate the consistency of the prioritization choices. Respondents were informed of the hypothetical nature of these exercises in advance. In the third question, respondents were asked to rate their level of agreement/disagreement, through a five-point Likert scale (1 "strongly disagree" and 5 "strongly agree"), with 17 statements created elsewhere (Pinho and Borges, 2015). These statements evaluate the: criterita for establishing priorities between patients (14 statements); identification of who should bear the responsibility for prioritizing patients ( 2 statements); and the belief that future pressures on state budgets can make these choices a reality (1 statement). The last question was aimed to recording the socio-demographic and health characteristics of the participants.

The validation of the questionnaire scale was performed through the test of validity and reliability. A high internal reliability (Cronbach's $\alpha 1 / 40.961$ ) was obtained.

\section{Participants}

There were 243 filled questionnaires. Table Al gives a detailed description of the sample and shows that, on average, the sample was better educated and had a higher income than would have been expected if the sample was truly representative of the general population (Croatian Bureau of Statistics, 2011).

\section{Analysis}

The quantitative analysis was performed through SPSS (24) statistical software. The data concerning the 14 statements regarding the prioritization criteria were subjected to a principal component analysis with varimax rotation, in order to identify the main substantive principles inherent in the patients' prioritization processes. The ANOVA test was performed to explore the influence of the main distributive principles when choosing the first patient to treat (first question). The ANOVA test, along with the Kruskal-Wallis test, was performed to test for possible associations between respondents' socio-demographic and healthcharacteristics and the level of importance assigned to the different statements displayed in the third question.

\section{Results}

Patient choice - only one patient can be treated (first question) and patient ranking - all patients can be treated but not at the same time (second question)

Table II summarizes respondents' choices concerning which patient to treat when not all can be attended to and the rankings of the patients. From the full sample, no one refused to select or order the patients. In the first question, most of the respondents (71.2 percent) gave top priority to Petar followed by Ruža (16.01 percent), Marija (7.8 percent) and finally Ivan (4.9 percent).

When an ordination of the patients was allowed (second question), Petar received the top priority, followed by the elderly patient (Ruža) and then Marija, with Ivan receiving, on average, the lowest priority. The responses to both questions suggest consistency between the scenarios.

\begin{tabular}{|c|c|c|c|c|c|c|}
\hline \multirow[b]{2}{*}{ Patient } & 1st question: choice of the only one patient & \multicolumn{5}{|c|}{ 2nd question: ranking of patients } \\
\hline & Freq. $(\%)$ & Rank 1 & Rank & Rank 3 & Rank 4 & Mean (median \\
\hline Petar & $173(71.2)$ & 124 & 76 & 38 & 5 & 1.7 (1) \\
\hline Ruža & $39(16)$ & 82 & 105 & 38 & 18 & $2.0(2)$ \\
\hline Marija & 19 (7.8) & 19 & 42 & 102 & 80 & $3.0(3)$ \\
\hline Ivan & $12(4.9)$ & 18 & 20 & 65 & 140 & $3.3(4)$ \\
\hline
\end{tabular}


Prioritization principles - responsibility for patients' prioritization and awareness that healthcare rationing can become real (third question)

Table III summarizes the respondents' level of agreement with 17 statements, covering the prioritization principles (ES1 to ES14), the definition of who should be making the rationing decisions (ES15 and ES16) and the perception regarding the need for rationing decisions (ES17).

The results show that the statements with the greatest level of agreement (agree and strongly agree) were: ES15 - this type of choices/decisions should always be taken by health professionals, followed by ES6 - priority should be given to children because they have not yet lived enough, ES5 - priority should be given to patients with an increased risk of life, ES7 - priority should be given to children because they are more fragile and need more protection, ES1 - all patients deserve equal priority and ES14 - priority should be given to more effective treatments.

These results show that Croatian respondents support a plurality of rationing principles. Their preferences suggest that the young are favored over the old, the more severely ill are favored over less severely ill; larger health gains are favored over lesser ones' and when patients' selection is not morally accepted, the lottery principle should prevail. Curiously, the majority of respondents agreed with the lottery principle (ES1), but excluded the "first come first served" criterion (ES2). This may be because they understand that the queue or waiting lists can be vulnerable to the influence of the wealthy, powerful and those well-connected.

It is also interesting to note that Croatian respondents seem to similarly value the gains in quality (ES4) and the extension of life (ES3), although a slight preference toward life extending is present. In relation to the responsibility for patient's prioritization, Croatian respondents seem to hold trust

Table III Scale application and descriptive analysis to prioritization patients, identifying who should be responsible for deciding whom to treat and the awareness of the rationing decisions becoming a reality

Variables

SDIS (\%) DIS (\%) NAND (\%) AGR (\%) SAGR (\%) Mean SD

ES1 All patients deserve an equal priority, and it's not up to anyone who to treat or not to treat

ES2 Patientsshould be treated according to their order of arrival-the first to arrive is the first to be treated

ES3 Priority should be given to patients who gain more years of life when treated -increase their life expectancy

ES4 Priority should be given to patients who gain more quality of life when treated, regardless of the growth of their life expectancy

ES5 Priority should be given to patients with an increased risk of life

ES6 Priority should be given to children because they have not yet lived long enough

ES7 Priority should be given to children because they are more fragile and need more protection

ES8 Priority should be given to elderly patients since they are more fragile and need more protection

ES9 Priority should be given to handicapped (physically or mentally disabled) patients

ES10 Priority should be given to most economically disadvantaged patients

ES11 Priority should be given to patients, who do not carry out risky behaviors like smoking, drinking, taking drugs, etc.

ES12 Priority should be given to patients who, with the treatment, are exempted from other treatments in the future

ES13 Priority should be given to patients who require cheaper treatments

ES14 Priority should be given to more effective treatments

ES15 This type of choices/decisions should always be taken by health professionals

ES16 Such choices/decisions should always be taken by managers/economists

\begin{tabular}{rrrrrrr}
11.2 & 10.5 & 20.3 & 21.0 & 37.1 & 3.62 & 1.367 \\
39.2 & 22.4 & 18.2 & 12.6 & 7.7 & 2.27 & 1.306 \\
7.7 & 12.6 & 31.5 & 28.0 & 20.3 & 3.41 & 1.170 \\
& & & & & & \\
6.3 & 14.7 & 39.2 & 28.0 & 11.9 & 3.25 & 1.050 \\
& & & & & & \\
5.6 & 8.4 & 23.1 & 26.6 & 36.4 & 3.80 & 1.184 \\
7.7 & 7.7 & 19.6 & 25.9 & 39.2 & 3.81 & 1.250 \\
11.9 & 9.1 & 18.9 & 24.5 & 35.7 & 3.63 & 1.362 \\
10.1 & 13.8 & 36.4 & 22.1 & 17.7 & 3.35 & 1.140 \\
11.2 & 13.3 & 41.3 & 23.8 & 10.5 & 3.09 & 1.113 \\
17.5 & 6.9 & 37.1 & 25.2 & 13.4 & 3.25 & 1.189 \\
21.0 & 17.5 & 23.8 & 25.2 & 12.6 & 2.91 & 1.332 \\
7.7 & 11.9 & 40.6 & 25.2 & 14.7 & 3.27 & 1.101 \\
& & & & & & \\
14.1 & 21.7 & 41.7 & 19.8 & 2.8 & 2.96 & 1.143 \\
9.8 & 10.5 & 21.0 & 33.6 & 25.2 & 3.54 & 1.249 \\
2.8 & 7.7 & 18.2 & 28.0 & 43.4 & 4.01 & 1.088 \\
& & & & & & \\
61.5 & 23.8 & 7.0 & 5.6 & 2.1 & 1.63 & 0.984 \\
19.6 & 14.0 & 30.1 & 20.3 & 16.1 & 2.99 & 1.335 \\
\hline & & & & & & \\
\hline
\end{tabular}

Notes: SDIS, strongly disagree; DIS, disagree; NAND, neither agree nor disagree; AGR, agree; SAGR, strongly agree 
in the health professionals to make the rationing decisions. Interestingly and contrary to what would be expected, the respondents do not seem to believe that rationing decisions will become a reality. Indeed, it seems that Croatian respondents have never thought about it ( 30 percent of the sample or 73 respondents neither agree nordisagree).

\section{Main rationing principles that support patients' prioritization}

Inorder toidentify themain distributivecriteria of prioritizing the patients, thestatementsfromES1 to ES14 were analyzed together and subjected to the factor analysis, conducted through a principal components analysis, utilizing the varimax rotation. Results from the Kaiser-Meyer-Olkin (KMO) test indicated that the factor analysis should beperformed (KMO 0.717). The statistical value of the Bartlett's test ( $\left.X^{2} 328.396\right)$ is significant ( $\left.p 00.01\right)$, and the correlations between variables are sultable for performing a factor analysis. The results were summarized in Table IV. $1 / 4$

Three factors emerged from the factor analysis (explaining 69.028 percent of the total variance of the data). All items loaded highly on the factors and no item loaded on more than one factor, supporting the independence of the dimensions. The factors can be framed in the following rationing principles: favoring the worst-off, ageism and maximizing health benefits.

Favoring the worst-off was the most important factor. The second factor highlights the aged-based rationing. Although it can be framed within a more general principle of favoring the worst-off, we decided to keep it apart, mainly because favoring younger patients is one of the most debated discrimination factors in healthcare accessing (McGough et al., 2005; Werntoft and Edberg, 2009; Reese et al., 2010; Callahan, 2012; Morreim et al., 2014). Finally, achieving efficiency was depicted by the preferences toward the cheapest and effective treatments, as well as those that ensure future savings for the health system.

\section{Relevance of the main rationing principles in choosing the first patient to treat}

The ANOVA test was performed to assess the relevance of each of the three main distributive principles, defined previously, when choosing which patient to treat when not all can be treated (first question - Table II). Table $V$ summarizes the main results.

ES8 - priority should be given to elderly patients since they are more fragile and need more protection

\subsection{7}

0.701

0.682

0.789

ES7 - priority should be given to children because they are more fragile and need more protection

ES6 - priority should be given to children because they have not yet lived long enough

ES13 - priority should be given to patients who require cheaper treatments

ES12 - priority should be given to patients who, with the treatment, are exempted from other treatments in the future

ES14 - priority should be given to more effective treatments

Eigenvalues/Rotation sums squared loadings

$\%$ variance

Notes: aExtraction method: principal component analysis; rotation method: varimax with Kaiser normalization

\section{Table V Relevance of the rationing principles in choosing the first patient to treat - ANOVA test}

\begin{tabular}{lccc} 
Hypothesis & Favoring worst-oft & Age factor & Efficiency factor \\
\hline $\begin{array}{l}\text { The choice of the first patient depends of the main principles assumed } \\
\text { Result }\end{array}$ & $\begin{array}{c}0.140(0.936) \\
\text { Not accept }\end{array}$ & $\begin{array}{c}8.883(0.000)^{* *} \\
\text { Accept }\end{array}$ & $\begin{array}{c}3.157(0.027)^{*} \\
\text { Accept }\end{array}$ \\
Notes: ${ }^{*} p 00.05 ;{ }^{* *} p 00.01$ & &
\end{tabular}


The results indicate that the age and the efficiency factors were crucial in determining the top priority of patients (the majority of respondents chose the child - Petar). These seem to suggest that respondents value both the chronological and the biological age of the patients. This is, however, merely speculative and requires further research. Some evidence suggests that, for example, physicians give precedence to the patients' biological, rather than chronological age (Werntoft and Edberg, 2009).

Determinants of the main rationing principles, the responsibility for patients' prioritization and the awareness that rationing healthcare can become real

Association between the respondents' characteristics and the level of agreement with the statements (thirdquestion). The ANOVAand Kruskal-Wallis tests were performed to explore the association between respondents' demographic and health condition characteristics, as well as the: main rationing principles; appointment of whom should bear the responsibility of patient selection; and the belief that rationing decisions will become a reality. A detailed description of the results can be found in Table All.

In relation to the degree of agreement with the distributive principles (top panel in Table All), we may conclude that the adherence to the general theory of Rawls was influenced by the respondents' religion. Being religious was also influential in the agreement with the age factor, along with the marital status and the level of education. We can only speculate about the association between being religious and favoring the worst-off, however, it does seem somewhat consistent. Croatia is traditionally a very religious country and according to the last census the majority of Croats (86 percent) are Catholics (Črpic' and Tanjic', 2015; Croatian Bureau of Statistics, 2011). The support for the efficiency criteria seems to be influenced by respondents' gender and self-rated health status. In the bottom panel of the Table All, gender seems to be a determinant when selecting the managers or economist to taking on the rationing decisions, while the preference for health professionals was explained by the respondents' professional situation. Agreater orientation toward future needs when prioritizing patients was related with the respondents' gender, age and marital status.

\section{Discussion and conclusion}

The rationing of healthcare is ethically complex. The transparency of the priority setting process is an important one, a central consideration when creating a fair healthcare system. The ethical rationing requires choices guided by reasonable, applicable principles. This study has three main research questions. We intend to examine the Croatian (according to opinions expressed by this sample) concerning which rationing principles should guide bedside rationing decision; whom should have the responsibility to make healthcare rationing choices; and the future of rationing healthcare in Croatia. The results obtained indicate that respondents, when faced with the need to select patients, exhibit a pluralism of distributive principles in line with international findings which suggests that no single principle allocates interventions justly (Exel etal., 2015; Gu etal., 2015; Pinho and Borges, 2015). In the moment of deciding which patient to treat, the respondents support the fair-innings argument, as well as the principles of the severity of the health condition, the patients' vulnerability, the lottery selection and the treatment outcomes. In general, respondents expressed a broader ethical notion of solidarity, mirrored in the concern exhibited toward the worst-off patients of society (namely, the elderly, the handicapped, the poorest and the youngest) and of the efficiency principles. The efficiency criterion received, however, the third position in the overall prioritization process. Concerning efficiency, respondents were more sensitive to mortality than to morbidity what diverges from the international evidence that reveal that quality of life is more important than simply staying alive (Exel et al., 2015).

Croatian respondents appoint health professionals as the parties that should be responsible for the patient selection process. This finding is in accordance with wider, international results (Coast, 2001; Litva etal., 2009; Botelho etal., 2014; Pinho and Borges, 2015). Regarding the future, it is interesting to note that the Croatians do not seem to be aware that the rationing decisions can become a reality. This result was unexpected, mainly because of the Croatia's rationing reforms 
undertaken in the recent years. This can happen due to insufficient media coverage of the rationing reforms, or even due to the lack of political debate regarding these complex issues.

One key strength of our study is its first attempt to collect evidence on the Croatian citizens' ethical values concerning the principles that should guide bedside rationing decisions.

The results should be interpreted with appropriate caution, given the non-random nature of the sample and its small size. It is a sample based on self-selection, which reflects the opinion of the more privileged members of society, who are active on the web. This particular sample limitation is mostly the result of the data collection process (online questionnaire). We are keenly aware of the challenges and ethical considerations of web-based preferences elicitation, namely, those related to sampling, sample representativeness and limitations resulting from the "digital divide," literacy and disability. It is worth saying, however, that there has been an increased interest in applying online questionnaires (Mulhern et al., 2013; Gilligan etal., 2014) and some studies found a broadly similar pattern of respondents across different modes of survey administrations (Damschroder et al., 2004; Rowen et al., 2016). Besides this sampling limitation, a particular drawback of the methodology used in this study is that it only used four vignettes. We are aware that four vignettes covering age, gender, illness, prognosis and the cause of illness may be insufficient to offer a full account of decision making. With only four vignettes there is potential to be conflating a number of variables which may jeopardize the clear definition of the ethical values supported by Croatian respondents. It is our contention that these drawbacks are overcome by the contribution of this study to obtain Croatian opinions about difficult and unfamiliar issues. Future research needs to address both of these problems. It would be useful to extend this preference elicitation to a representative sample of the Croatian population (larger scale version) and also to health professionals. Comparing the views of both stockholders would allow exploring whether the value judgments expressed by Croatian health professionals are aligned with those of non-professional groups. Besides, knowing the ethical value judgments of health professionals would allow defining health team's decisions instead of single decisions. Single decisions are less possible and realistic to be accepted by the patient or other involved people. It would also be useful to conduct further investigation with a greater number of vignettes in order to tease out the reasoning behind the ranking more clearly.

Overall, our findings suggest that although the Croatian respondents did not believe that establishing priorities among patients can become more visible in a near future they seem to have an opinion concerning social criteria to be applied. This seems to suggest that the general public seems to be more reasonable than health sector policy makers and/or decision makers may think. In this context, Croatian political decision makers have the opportunity to start a public debate on this matter and begin to develop systematic criteria to select whom to treat when resources are scarce. Besides, Croatian respondents rely on health professionals to make rationing decisions on their behalf. Thus, any development action must necessarily involve population and health professionals.

\section{References}

Beauchamp, T. and Childress, J. (2012), Principles of Biomedical Ethics, Oxford University Press, Oxford.

Botelho, A., Pinho, M. and Veiga, P. (2014), "Who should participate in health care priority setting and how should priorities be set? Evidencefrom aPortuguese survey", RevistaPortuguesadeSaúde Pública, Vol. 31 No. 2, pp. 214-22.

Callahan, D. (2012), "Must we rationhealth care for theelderly?", JournalofLawandMedicalEthics, Vol. 40 No. 1, pp. 10-6.

Coast, J. (2001), "Citizens, their agents and health care rationing: an exploratory study using qualitative methods", Health Economics, Vol. 10, pp. 159-74.

Cookson, R. and Dolan, P. (1999), "Public views on health care rationing: a group discussion study", Health Policy, Vol. 49, pp. 63-74.

Coulter, A. and Ham, C. (2000), The Global Challenge of Healthcare Rationing, Open University Press, Buckingham. 
Croatian Bureau of Statistics (2011), "Census of population, household and dwellings 2011", available at: www.dzs.hr/Eng/censuses/census2011/censuslogo.htm (accessed May 22, 2016).

Damschroder, L., Baron, J. and Hershey, J. (2004), "The validity of person trade-off methods: randomized trial of computer elicitation versus face-to-face interview", Medical Decision Making, Vol. 24, pp. 170-80.

Daniels, N. (1985), Just Health Care, Cambridge University Press, Cambridge.

Diederich, A. and Salzmann, D. (2015), "Public preferences regarding therapeutic benefit, costs of a medical treatment and evidence-based medicine as prioritization criteria", Journal of Public Health, Vol. 23 No. 3 , pp. 137-48.

Dzakula, A., Sagan, A., Pavic, N., Loncarek, K. and Sekelj-Kauzlaric, K. (2014), "Croatia: health system review - health systems in transition", European Observatory on Health Systems and Policies, Vol. 16 No. 3, pp. 1-162.

Eurostat (2016), "Statistics explained", European Commission, available at: http://ec.europa.eu/eurostat/ statisticsexplained/index.php/Unmet_health_care_needs_statistics (accessed May 21, 2016).

Exel, J., Baker, R., Mason, H., Donaldson, C. and Brouwer, W. (2015), "Public views on principles for health care priority setting findings of a European cross-country study using Q methodology", Social Science \& Medicine, Vol. 126, ph. 128-37.

Gilligan, C., Kypri, K. and Bourke, J. (2014), "Social networking versus Facebook advertising to recruit survey respondents: a quasi-experimental study", JMIR Research Protocols, Vol. 3, p. e48.

Gu, Y., Lancsar, E., Ghijben, P., Butler, J. and Donaldson, C. (2015), "Attributes and weights in healtheare priority setting: a systematic review of what counts and to what extent", Social Science \& Medicine, Vol. 146,pp. 41-52.

Jonsen, A. (1986), "Bentham in abox: technologyassessment and healthcareallocation", LawMedicineand Health Care, Vol. 14, pp. 172-4.

Kaplan, G. and Baron-Epel, O. (2013), "The public's priorities in health services", Health Expectations, Vol. 18 No. 5, pp. 904-17.

LeGrand, J. (1991), Equity and Choice. An Essay in Economics and Applied Philosophy, Routledge/Taylor \& Francis Group, London.

Litva, A., Canvin, K., Shepherd, M. , Jacoby, A. and Gabbay, M. (2009), "Lay perceptions of the desired role and type of user involvement in clinical governance", Health Expectations, Vol. 12 No. 1, pp. 81-91.

McGough, L., Reynolds, S., Quinn, T. and Zenilman, J. (2005), "Which patients first? Setting priorities for antiretroviral therapy where resources are limited", American Journal of Public Health, Vol. 95, pp. 1173-80.

Mastilca, M. and Kusec, S. (2005), "Croatian healthcare system in transition, from the perspective of users", British Medical Journal, Vol. 331, pp. 223-7.

Mitton, C. and Donaldson, C. (2004), Priority Setting Toolkit: A Guide to the Use of Economics in Healthcare Decision Making, BMJ Books, London.

Morreim, H., Antiel, R., Zacharias, D. and Hall, D. (2014), "Should age be a basis for rationing health care?", American Medical Association Journal of Ethics, Vol. 16 No. 5, pp. 339-47.

Mulhern, B., Longworth, L., Brazier, J., Rowen, D., Bansback, N., Devlin, N. and Tsuchiya, A. (2013), "Binary choice health state valuation and mode of administration: head-to-head comparison of online and CAPI", Value in Health, Vol. 16 No. 1, pp. 104-13.

Persad, G., Wertheimer, A. and Emanuel, E. (2009), "Principles for allocation of scarce medical interventions", Lancet, Vol. 329, pp. 224-7.

Pinho, M. and Borges, P. (2015), "Bedside healthcare rationing dilemmas: a survey from Portugal", International Journal of Human Rights in Healthcare, Vol. 8 No. 4, pp. 233-46.

Pinho, M., Borges, A. and Zahariev, B. (2017), "Bedsides healthcare rationing dilemmas: a survey from Bulgaria and comparison with Portugal”, Social Theory \& Health, Vol. 15 No. 3, pp. 285-301.

Rawls, J. (2002), A Theory of Justice, Oxford University Press, Oxford.

Reese, P., Caplan, A., Abt, P. and Karlawish, J. (2010), "How should we use age to ration health care? Lessons from the case of kidney transplantation", Journal of the American Geriatrics Society, Vol. 58 No. 10, pp. 1980-6. 
Rogge, J. and Kittel, B. (2016), "Who sh 1 not be treated: public attitudes on setting health care priorities by person-based criteria in 28 nations", PLoS One, Vol. 11 No. 6.

Rowen, D., Brazier, J., Keetharuth, A. and Tsuchiya, A. (2016), "Comparison of modes of administration and alternative formats for eliciting societal preferences for burden of illness", Applied Health Economics and Health Policy, Vol. 14 No. 1, pp. 89-104.

Vončina, L., Strizrep, T., Bagat, M., Pezelj-Duliba, D., Pavič, N. and Polašek, O. (2012), "Croatian 2008-2012 health insurance reform: hard choices toward financial sustainability and efficiency", Croatia Medical Journal, Vol. 53 No. 1, pp. 66-76.

Werntoft, E. and Edberg, A.-K. (2009), "The views of physicians and politics concerning age-related prioritization in healthcare", Journal of Health Organization and Management, Vol. 23 No. 1, pp. 38-52.

Whitty, R., Rundle-Thiele, S. and Scuffham, P. (2008), "Insights into public preferences for pharmaceutical funding", International Journal of Pharmaceutical and Health Marketing, Vol. 2, pp. 216-34.

WHO Regional Office for Europe (1996), European Health Care Reforms: The Ljubljana Charter on Reforming Health Care, WHO Regional Office for Europe, Copenhagen.

Williams, A. (1997), "Intergenerational equity: an exploration of the Fair-Innings argument", HealthEconomics, Vol. 6, pp. 117-32.

Williams, A. and Cookson, R. (2000), "Equtity in health", in Culyer, A. and Newhouse, P. (Eds), Handbook of Health Economics, NorthHolland/Elsevier.

\section{Further reading}

Callahan, D. (1985), Setting Limits: Med gal Goals in an Ageing Society, Georgetown University Press, Washington, DC.

Ziebertz, H.-G. and Črpic', G. (2015), Retigien and Human Rights: An International Perspective, Springer.

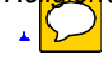




\section{Appendix}

Table Al Demographic, socio-economic and health characteristics of the sample (percentage)

Characteristics

Respondents (\%) (n1/4243)

\section{Gender}

Female

Male

51.0

Total

49.0

Age (years)

(18-24)

(25-34)

(35-44)

(45-54)

W54

Total

23.8

58.0

7.7

4.9

5.6

100

Marital status

Single

Married

35.0

Divorced

2.1

Widow

0.0

Total

100

Education

Elementary studies

Secondary studies

31.5

Higher studies/degree

21.0

Master or PhD

45.5

Total

100

Professional situation

Self-employed

6.3

Employee

57.3

Unemployed

10.5

Student

24.5

Retired

1.4

Total

100

Netmonthlyincome (€)

Less or equal 485

44.1

$(486-1,000)$

$(1,001-1,500)$

W 1,501

13.3
8.3

Total

100

Private insurance

Yes

30.1

No

69.9

Total

100

Self-rated health

Very good

Good

44.8

Average

39.2

Bad

Verybad

14.0

2.1

Total

Religious

Yes

No

52.4

Total

47.6

100 
Table All Association between respondent's characteristics and the level of agreement with priority setting criteria, responsibility for rationing decision and belief in eventual reality of the prioritization

\begin{tabular}{|c|c|c|c|}
\hline \multicolumn{4}{|c|}{ ANOVA test } \\
\hline Characteristics & Favoringworst-off & Age factor & Efficiency \\
\hline Gender & - & - & $2.910(0.090)^{*}$ \\
\hline Age & - & - & - \\
\hline Marital status & - & $3.651(0.028)^{* *}$ & - \\
\hline Education & - & $2.680(0.049)^{* *}$ & - \\
\hline Professional situation & - & - & - \\
\hline Net monthly income & - & - & - \\
\hline Private insurance & - & - & - \\
\hline Self-rated health & - & - & $2.232(0.087)^{*}$ \\
\hline \multirow[t]{2}{*}{ Religious } & $4.977(0.027)^{* *}$ & $5.558(0.020)^{* *}$ & - \\
\hline & Responsibility & $\begin{array}{l}\text { Kruskal-Wallis test } \\
\text { rationing decisions }\end{array}$ & \\
\hline Characteristic & Health professionals (ES15) & Managers/Economists (ES16) & Possible reality of patient selection (ES17 \\
\hline Gender & - & $2.776(0.096)^{*}$ & $4.180(0.041)^{* *}$ \\
\hline Age & - & - & $10.332(0.035)^{* *}$ \\
\hline Marital status & - & - & $6.741(0.034)^{* *}$ \\
\hline Education & - & - & - \\
\hline Professional situation & $11.502(0.021)^{* *}$ & - & - \\
\hline Net monthly income & - & - & - \\
\hline Private insurance & - & - & - \\
\hline Self-rated health & - & - & - \\
\hline Religious & - & - & - \\
\hline
\end{tabular}

